\title{
Avaliação das Características de Personalidade de Goleiros Profissionais e Amadores
}

\author{
Evaluation of the personality characteristics of
} professional and amateur goalkeepers
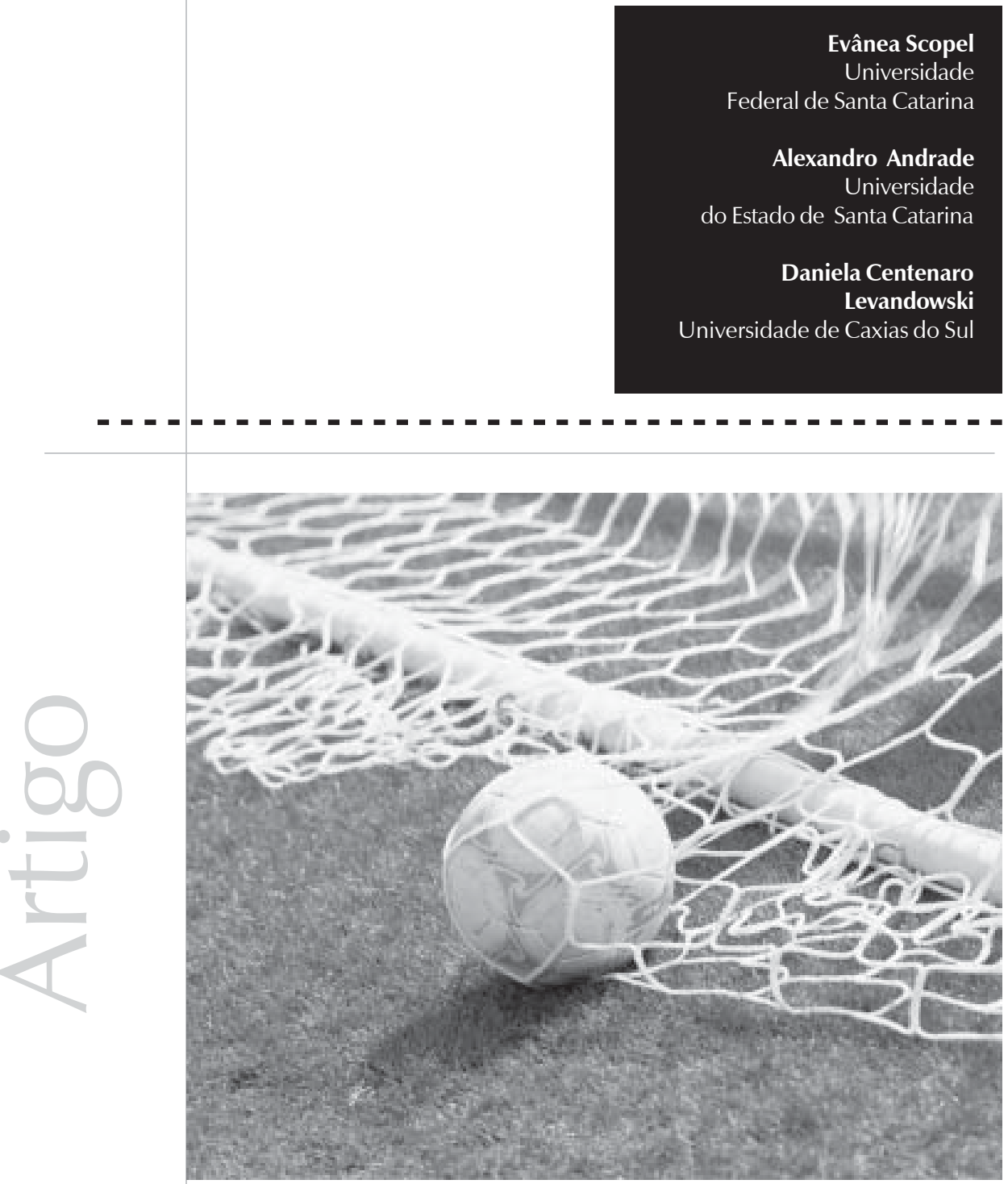


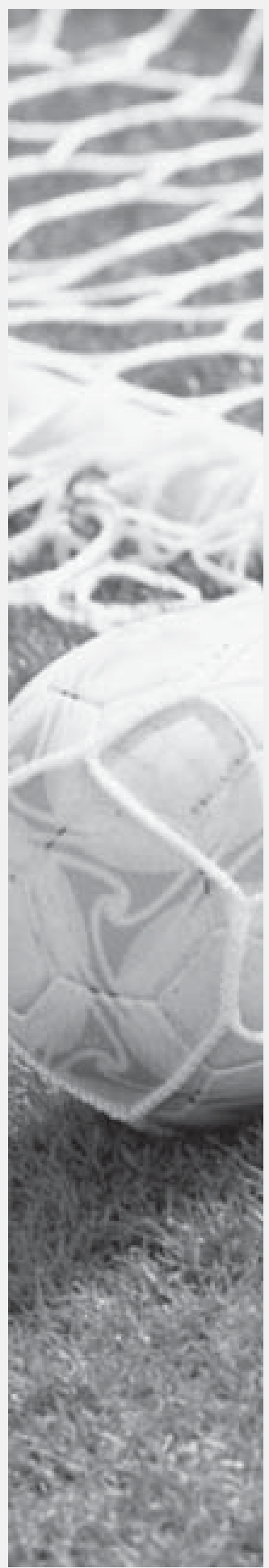

Resumo: O presente estudo teve como objetivo identificar as características de personalidade de goleiros profissionais e amadores do futebol de campo, investigando as atitudes e funções psíquicas mais utilizadas e avaliando diferenças e semelhanças entre os grupos. $\mathrm{O}$ instrumento utilizado foi o questionário de avaliação tipológica, de Zacharias(1994), baseado na teoria junguiana. A amostra foi composta de 28 goleiros ( 14 profissionais e 14 amadores). Verificou-se, em ambos os grupos, que a atitude predominante foi a extroversão, e a função psíquica dominante foi a sensação. Atletas que utilizam essa atitude gostam de variedade e ação durante as atividades, e são impacientes com treinos longos e lentos, além de serem pessoas mais práticas que teóricas. Predominaram os tipos psicológicos sensação introvertida com pensamento e sensação extrovertida com pensamento. Os resultados obtidos levaram a pensar na existência de certas características de personalidade comuns a esses atletas, uma vez que se encontraram similaridades nas características de personalidade entre goleiros profissionais e amadores.

Palavras-chave: Psicologia do esporte, características de personalidade, goleiros, teoria junguiana.

Abstract:The aim of the study was to identify the personality characteristics of professional and amateur soccer goalkeepers, examining the attitudes and psychic functions more utilized by them to evaluate differences and similarities between groups. QUATI was the test employed to evaluate these aspects in a sample composed by 28 goalkeepers ( 14 amateurs and 14 professionals). The predominant attitude was extroversion and the dominant psychic function was sensation, in both groups. Athletes with this attitude enjoy variety and action during activities and get impatient with long and slow trainings, being more practical than theoretical. The psychological types that had predominated were introverted sensation with thought and "extroverted sensation with thought". The results indicated the existence of common personality characteristics of these athletes because of the similarities found in the personality characteristics of professional and amateur goalkeepers.

Key words: sport Psychology, personality characteristics, goalkeepers, Jung theory. 
"Apesar de a Psicologia já possuir uma longa história com os esportes, apenas muito recentemente é que ela se tem incorporado como ferramenta indispensável à preparação de atletas. Ao menos, em nosso país."
O Brasil, que tem os olhos primordialmente voltados para o futebol, mobiliza recursos financeiros e o que há de mais evoluído em termos de preparação física, técnica, tática e tecnológica para que seus jogadores extrapolem o limiar de suas performances. Entretanto, apesar da grande ênfase na técnica, sabe-se que as questões emocionais desses atletas só recentemente passaram a ser levadas em conta. Luccas (1998, p. 68) afirma que: "Apesar de a Psicologia já possuir uma longa história com os esportes, apenas muito recentemente é que ela se tem incorporado como ferramenta indispensável à preparação de atletas. Ao menos, em nosso país." De fato, reportando-nos aos cursos de graduação em Psicologia, veremos que é dada pouca ou nenhuma atenção ao esporte. De acordo com Epiphanio (1999), assim como com Rúbio (1999), até esta data, os cursos de Psicologia no Brasil não incluíam, em seu currículo, uma disciplina específica obrigatória de Psicologia no ou do esporte.

De qualquer modo, dentre as várias possibilidades de atuação que foram sendo organizadas pelo psicólogo que atua no âmbito esportivo, o diagnóstico de perfis individuais e grupais é considerado de fundamental importância para que intervenções posteriores possam ser realizadas de maneira eficaz. Para Brandão (2003), nesse perfil, é necessário investigar alguns aspectos da personalidade, concentração, estresse, estabilidade emocional (como o atleta reage antes, durante e após as competições), liderança e interação social dos atletas.

Nesse sentido, para que se pudesse realizar um estudo que contemplasse a avaliação de algumas dessas características, investigou-se, dentro do futebol de campo, a posição de goleiro, visto ser essa uma função diferenciada daquela dos demais integrantes da equipe. A partir do acompanhamento dos treinos, podem ser percebidas as peculiaridades da posição desse atleta em relação às demais, desde as vestimentas, os treinos diferenciados e, aparentemente, mais exaustivos do que os do restante do grupo, até a pouca interação com os demais colegas.

A escolha de uma posição em uma equipe de futebol significa assumir responsabilidades. Quando alguém assume a função de goleiro, inúmeras dificuldades devem ser superadas, tais como: os diversos e exaustivos treinamentos, a incompreensão do torcedor diante de uma falha, a necessidade de autodisciplina, o controle emocional e a solidão. Assim, esse integrante, de fundamental importância em uma equipe de futebol, treina diária e intensamente, e deve estar preparado para entender as críticas da torcida, bem como ser "rigoroso consigo mesmo, disciplinado em suas ações e atitudes dentro e fora do campo, devendo controlar suas emoções, utilizando-as adequadamente a fim de maximizar o nível de seu desempenho" (Viana, 1995, p.11).

Para que consiga desempenhar de uma forma adequada suas diversas funções, esse atleta deverá possuir atributos físicos e psicológicos diferentes dos demais jogadores. Csanádi (apud Viana, 1995) elenca algumas qualidades físicas e psíquicas que considera importantes para a execução adequada da função de goleiro: estatura entre 1,75 e 1,90m, peso proporcional à altura, força e potência muscular, elasticidade, velocidade de deslocamento, agilidade e resistência geral. Já em relação às habilidades psíquicas, considera que as importantes são: valentia e coragem, tranqüilidade, capacidade de reações múltiplas, força de vontade e confiança. No entanto, é tarefa difícil encontrar, na literatura, as características de personalidade de goleiros, tendo em vista que há um número muito reduzido de material bibliográfico se considerarmos a imensa quantidade de técnicos, preparadores físicos, preparadores de goleiros e médicos que trabalham com o desporto (Viana, 1995). Dentre os poucos 
relatos encontrados, menciona-se a pesquisa realizada por Barretto (2003), que encontrou, entre atletas que ocupam a posição de goleiro, o predomínio de uma atitude mais introvertida, assim como Matarazzo (1997), que afirma que jogadores de defesa tendem, preferencialmente, a essa atitude.

Tendo em vista as diferenças físicas e psíquicas em relação aos outros jogadores da equipe, objetivou-se traçar algumas características de personalidade desses atletas (goleiros). Este trabalho pode auxiliar técnicos e preparadores físicos a compreender mais adequadamente o "jeito de ser" de cada goleiro, para que possam lidar melhor com cada um.

Fazer um diagnóstico de características de personalidade de atletas deve ter uma finalidade para quem é avaliado e para quem solicitou o trabalho. Para o avaliado, serve como um meio de autoconhecimento; para a comissão, serve para ampliar seu conhecimento sobre determinado atleta ou grupo, e, a partir das características diagnosticadas, procurar lidar com cada qual de acordo com suas características. Indiretamente, atingirão um melhor desempenho, pois cada pessoa prefere ser tratada de acordo com o seu jeito de ser e agir no mundo.

Assim sendo, o presente estudo teve como objetivo identificar as características de personalidade, com base na teoria junguiana, de goleiros profissionais e amadores que atuam no futebol de campo, investigando também quais as atitudes e funções psíquicas mais utilizadas por eles, examinando as diferenças e semelhanças entre os grupos.

\section{Método}

Este estudo se caracteriza como descritivo exploratório (Rudio, 1986), pois teve como objetivo identificar as características de personalidade, com base na teoria junguiana, de goleiros profissionais e amadores que atuam no futebol de campo.
A população do estudo foi composta por goleiros amadores e profissionais de futebol de campo. A amostra foi do tipo intencional estratificada, sendo constituída por 28 goleiros ( 14 amadores e 14 profissionais). Os amadores disputavam o campeonato municipal da cidade de São Marcos (RS), suas idades variaram entre 20 e 37 anos $(\mathrm{X}=25$ anos), tinham carga de treinamento inferior a quinze horas semanais e possuíam outra profissão, independentemente do futebol. Os profissionais disputavam campeonatos regionais, estaduais e nacionais e estavam vinculados a um clube esportivo da cidade de Caxias do Sul (RS). A idade desses atletas variou entre 17 e 33 anos ( $X=19$ anos), e a carga de treinamento era superior a quinze horas semanais, não possuindo eles outra profissão além do futebol.

Foi utilizado, como instrumento para a coleta dos dados, o QUATI - questionário de avaliação tipológica (Zacharias, 1994) - para identificar as características de personalidade e verificar as atitudes e funções psíquicas mais utilizadas por esses atletas. Esse instrumento consta de 102 questões fechadas com opção de resposta ("a" ou " $b$ ") sobre situações comuns do cotidiano. Ao atleta, foi solicitado que refletisse sobre o que ele efetivamente faria ou não frente às situações propostas, escolhendo uma das opções.

Os dados foram tratados por meio de estatística descritiva para identificar as atitudes e funções psíquicas mais utilizadas pelos goleiros e as diferenças e semelhanças entre os grupos.

\section{Limitação do estudo}

Por ser utilizado somente um instrumento de avaliação psicológica, os dados aqui apresentados dizem respeito a uma das inúmeras formas de proceder diagnosticamente em uma população esportiva específica. Portanto, as características de personalidades diagnosticadas através deste teste são apenas parte de toda uma dinâmica de funcionamento de personalidade. 


\section{Apresentação e discussão dos resultados}

Para determinar um tipo psicológico, primeiramente identificou-se a orientação do atleta: para o mundo interno (introversão) ou para a realidade externa (extroversão). Posteriormente a isso, analisou-se qual das quatro funções psicológicas o atleta preferia utilizar (pensamento, sentimento, sensação ou intuição). Dessa forma, as atitudes foram combinadas às quatro funções, constituindo, assim, os dezesseis tipos psicológicos existentes na teoria junguiana.

Quanto à atitude dos goleiros, pode-se verificar, em ambos os grupos, que a extroversão apareceu como predominante (figura1). Nesse caso, os jogadores descarregam suas emoções na medida em que elas surgem, podendo, dessa forma, agir impulsivamente frente às situações. De acordo com Matarazzo (1997), são atletas que gostam de variedade e ação durante suas atividades e são impacientes com treinos longos e lentos, preferindo realizar as suas tarefas com as outras pessoas, diferentemente dos introvertidos. Observou-se também, em um estudo conduzido por Garland (1990) em líderes de futebol colegial, que a característica de personalidade extroversão interferia positivamente na performance desses atletas. Em um outro estudo, realizado por Egan (2003), verificaram-se também altos escores de extroversão em escaladores do Monte Everest.

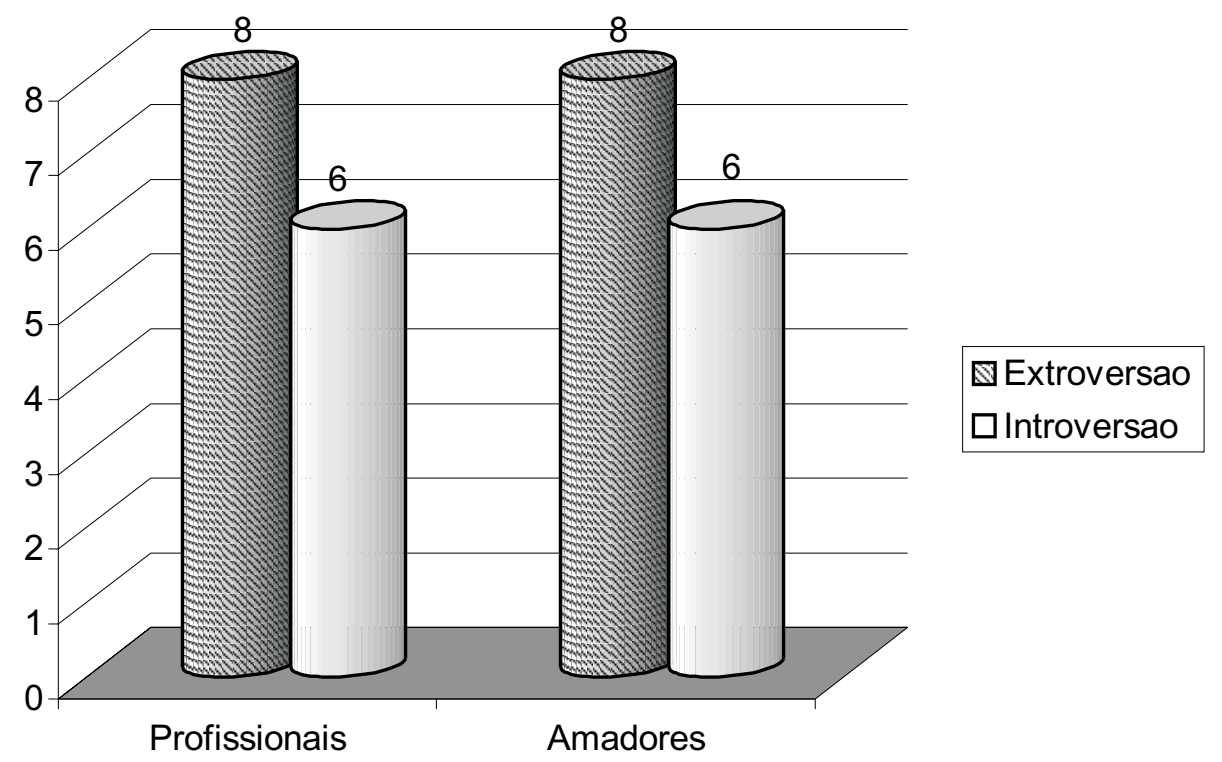

Figura 1: Avaliação tipológica em relação à atitude dos goleiros profissionais e amadores

Essa característica de personalidade de orientação extrovertida pode ser um ponto favorável do perfil psicológico desses atletas, já que os treinamentos dos goleiros requerem, para cada fundamento técnico, uma forma diferente de treino; ao mesmo tempo em que necessitam de muita ação para realizá-los, podem tornar-se, por vezes, exaustivos. Essa atitude também promove sociabilidade, permitindo que o indivíduo se sinta à vontade no meio de outras pessoas no sentido de focalizar sua atenção no mundo externo, ao contrário dos introvertidos, que dirigem sua atenção para o mundo interno das idéias e da compreensão. Acredita-se que essa sociabilidade e a facilidade de quem utiliza a extroversão enquanto atitude no trato com as pessoas é um ponto positivo para 
quem está na função de goleiro, isso porque o trabalho que esse atleta desenvolve requer a interação com os membros da equipe e da comissão técnica, tendo em vista que uma das suas tarefas é orientar os companheiros de equipe, por ser um jogador que tem a visão geral do posicionamento do time adversário. Assim, a atitude mais extrovertida favorece o exercício dessa função com maior eficiência.

Observa-se, por outro lado, na figura 1, que um número relativo de goleiros (tanto profissionais quanto amadores) apresentou a atitude de introversão. Esses dados estão de acordo com os estudos de Barreto (2003), que encontrou, entre goleiros, uma atitude mais introvertida, assim como Matarazzo (1997), que afirma que jogadores da defesa tendem, preferencialmente, a essa atitude. Esse resultado talvez se deva ao fato de que a função do goleiro ocorra de maneira mais individualizada, com menor interação com os demais membros da equipe, e os treinos tendam a ser mais solitários, o que condiz com a atitude introvertida.

Quanto à função psíquica dominante (figura 2), a sensação e a intuição predominaram na maioria dos goleiros, sendo a sensação a mais evidente. Isso significa que a maioria dos jogadores recebe a informação através dos órgãos dos sentidos e observa o que é concreto, pois são dependentes do ambiente físico/material, deixando de lado uma atitude mais reflexiva, o que os torna mais práticos que teóricos.

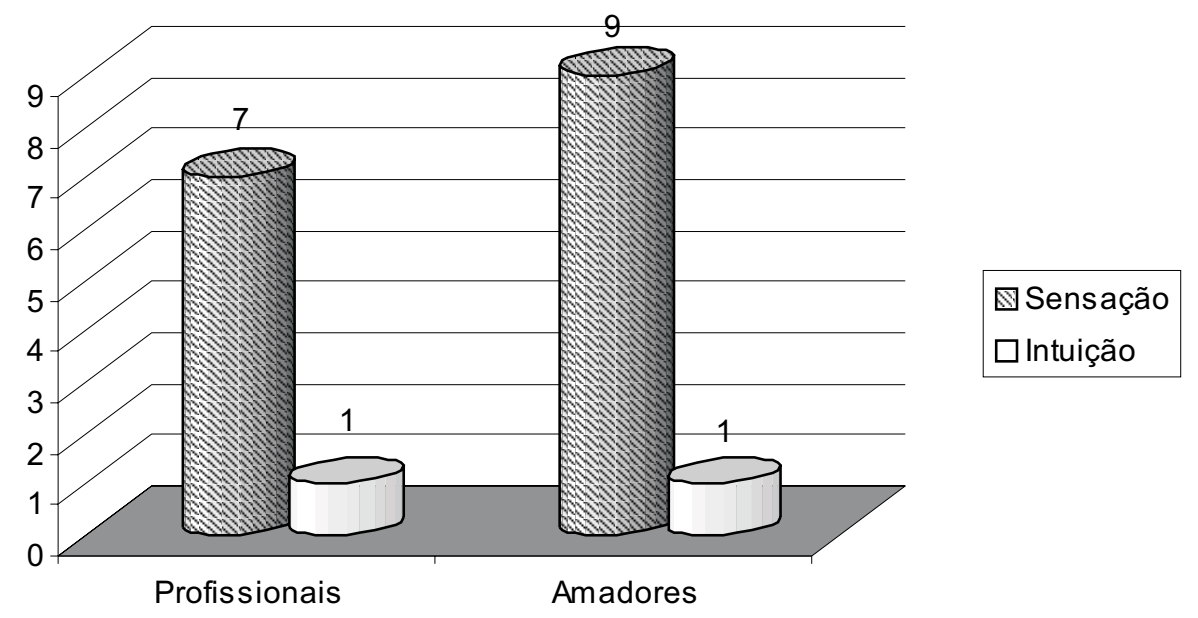

Figura 2: Avaliação tipológica em relação à função psíquica dominante dos goleiros profissionais e amadores

Essas evidências nos levam a pensar em duas hipóteses sobre a predominância da função psíquica sensação: uma das hipóteses seria que, por utilizarem o corpo (órgãos do sentido) para a execução das tarefas, a predominância da sensação se daria em função dos treinos, que são organizados de forma mecânica, e, por isso, não proporcionam ao atleta a possibilidade de refletir sobre o que está treinando. De fato, o goleiro executa, em seus treinos, inúmeras vezes, o fundamento técnico exigido, até que o faça com a maior perfeição possível, principalmente entre os profissionais. A outra hipótese seria que, em função de os goleiros amadores também apresentarem como 
De acordo com Matarazzo (1997), muitas vezes, os atletas, na busca da perfeição de um movimento, acabam deixando de lado sua intuição. predominância a função sensação, mesmo que estes não treinem de forma tão intensiva, a sensação estaria ativada no desenvolvimento psíquico do atleta, sendo inerente ao indivíduo. Infelizmente, considerando essas duas hipóteses, não foi possível, neste estudo, avaliar se a função sensação estava ligada ao tipo de treinamento - o meio influenciando o indivíduo - ou se, em função de uma predisposição inata, o indivíduo escolheria a posição de goleiro.

Em relação às preferências em situações de treino, Matarazzo (apud Franco, 2000) comenta que os sensitivos gostam que sejam mostrados exemplos das tarefas de treinamento, de maneira simples e prática, adaptando-se facilmente à rotina. Estas são também características importantes para qualquer atleta e também para um goleiro, pois, devido aos constantes treinos, faz-se indispensável certo grau de tolerância para a adaptação às rotinas de treinamento. Assim, mesmo com a predominância da atitude de extroversão entre os goleiros, o que poderia levar a uma predisposição à impaciência com treinos longos, detectou-se que eles têm facilidade em se adaptar às rotinas impostas pelos treinamentos e pelas competições, muito provavelmente, em virtude da função sensação. Essa situação parece ser ainda mais positiva para os atletas profissionais em virtude da elevada carga de treinamento e das rotinas de competição, que requerem, desses jogadores, longos períodos de concentração e isolamento antes dos jogos.

A sensação também se torna função importante na vida dos atletas, principalmente dos profissionais, uma vez que o estresse gerado pela pressão dos patrocinadores, da torcida, da mídia e dos dirigentes, para o desempenho ideal, pode ser considerado uma rotina à qual esses goleiros devem se adaptar. Nota-se que, na análise dos dados, a área intuição está sendo pouco explorada, pois apenas em dois dos goleiros essa função foi predominante. Isso significa que as impressões das situações que vivenciam não são influenciadas pela imaginação, o que, no esporte, pode acarretar falta de criatividade ou de confiança. De acordo com Matarazzo (1997), muitas vezes, os atletas, na busca da perfeição de um movimento, acabam deixando de lado sua intuição. Durante os treinamentos, são pouco exploradas as situações de jogadas não simuladas, ou seja, o treino está condicionado a jogadas préestabelecidas pelo preparador de goleiros. Por exemplo, o treinador sempre define se os chutes serão para a esquerda, para a direita ou para o canto superior esquerdo. Mesmo que a técnica do fundamento deva ser incansavelmente treinada para cada uma dessas posições, o atleta fica condicionado àquele movimento, portanto, a sua imaginação não é estimulada. Apenas nos jogos simulados entre as equipes é que se reproduzem as situações de jogo "da vida real." Acredita-se que o desenvolvimento balanceado da atitude oposta, nesse caso, a intuição, seja imprescindível para que se possa executar um trabalho mais integrado entre a técnica do fundamento e o improviso.

No que diz respeito à função auxiliar, ou seja, aquela que dá suporte à função dominante, as funções pensamento e sentimento foram as que apareceram em maior número entre as respostas (figura 3). Já entre as duas funções, a que predominou, tanto em goleiros profissionais como em amadores, foi o pensamento. Isso significa que, apesar de apresentarem a atitude extroversão, que lhes proporciona preferência por estar com pessoas e tendência à sociabilidade, seus relacionamentos se baseiam na razão, suprimindo-se as questões ligadas a sentimentos. Até certo ponto, isso pode ser prejudicial; por exemplo, ao apresentarem a tendência de querer que os outros sejam tão lógicos e analíticos quanto eles, podem gerar conflito, visto que, na equipe, cada qual tem seu jeito de ser. Por outro lado, sendo pessoas que conseguem valorizar a lógica sobre $o$ 
sentimento, em momentos críticos do jogo, com a pressão da torcida, por exemplo, esses atletas podem controlar a emoção, conseguindo manter o equilíbrio, não alterando seu desempenho. Sendo assim, utilizar o pensamento, nessas situações, tornar-se-ia um ponto favorável. Entretanto, é importante que possam também trabalhar sua função sentimento, pois o desenvolvimento equilibrado das duas funções é que irá permitir uma forma mais adequada de ser e agir no mundo

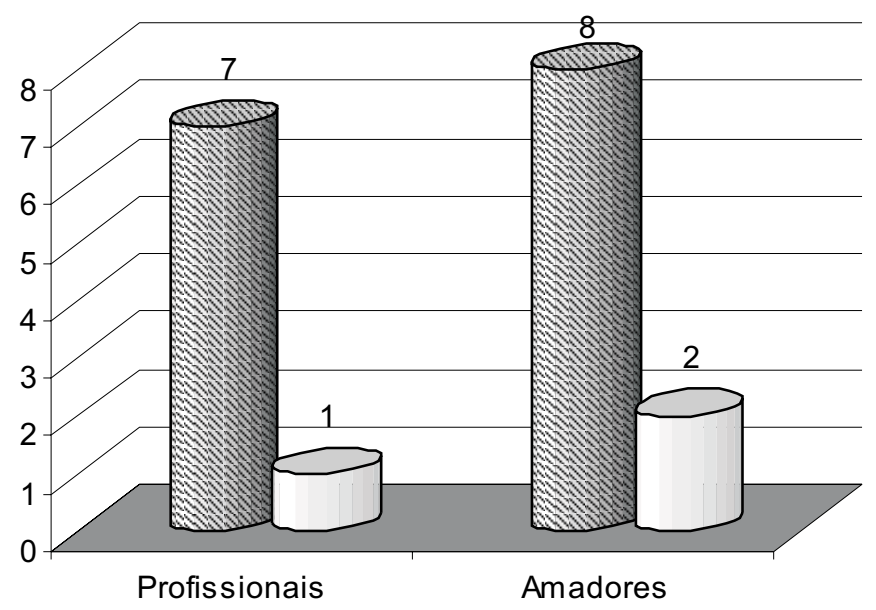

\begin{tabular}{l} 
QPensamento \\
$\square$ Sentimento \\
\hline
\end{tabular}

Figura 3: Avaliação tipológica em relação à função psíquica auxiliar dos goleiros profissionais e amadores

No que concerne ao "tipo psicológico", a tabela 1 mostra que, apesar de existirem dezesseis combinações possíveis, os tipos sensação introvertida com pensamento e sensação extrovertida com pensamento preponderaram entre os goleiros, tanto entre os amadores quanto entre os profissionais. Observa-se que as funções dominante e auxiliar são as mesmas nos dois tipos psicológicos, diferenciando-se os grupos somente quanto à atitude (introversão e extroversão), ou seja, a forma de direcionar a energia psíquica é peculiar a cada um, porém, para ambos os grupos, há a tendência de serem pessoas que vivem no "aqui-e-agora", intensas na busca incansável pelo prazer, ou seja, vivem "agora" e pensam depois.

Segundo Zacharias (2000), as pessoas que têm como predominância o tipo psicológico sensação introvertida com pensamento caracterizam-se por buscarem atividades que requeiram concentração e grande responsabilidade, ao mesmo tempo em que se dedicam ao trabalho a que se propõem de forma disciplinada e perseverante. Esse autor relata, ainda, que pessoas com esse perfil demonstram interesse em trabalhos práticos, nos quais esteja bem claro o que e como se deve fazer, evitando o que for teórico. Reportando-nos à posição de goleiro, veremos que essas características são importantes para essa posição, pois os treinamentos e competições exigem elevada concentração, responsabilidade, disciplina, perseverança e praticidade. Vale ressaltar que uma das dificuldades que esse tipo psicológico enfrenta é a tendência a esperar que as outras pessoas sejam tão lógicas e analíticas quanto eles mesmos. Por isso, é importante que utilizem sua percepção para compreender os demais, destaca Zacharias (2000).

Em relação ao tipo psicológico sensação extrovertida com pensamento, este se caracteriza por pessoas que apreciam esportes. De acordo com Zacharias (2000), são tolerantes e se adaptam 
facilmente às situações. Essa facilidade faz com que, muitas vezes, as pessoas com as quais convivem também se adaptem, pois, segundo esse autor, são pessoas que se caracterizam por grande popularidade e, por isso, suas sugestões e pontos de vista são geralmente ouvidos e seguidos. Tais características também seriam importantes para um goleiro, pois uma de suas funções é orientar a equipe, e, tendo tal facilidade em liderar, esse papel se tornaria mais viável. Esses indivíduos têm interesse maior em assuntos práticos, pouco se interessando por assuntos teóricos. Novamente, percebe-se aqui a preferência pela prática, importante para a posição de goleiro, levando em conta que seus treinamentos se processam considerando exclusivamente esse aspecto, ou seja, o aperfeiçoamento de habilidades práticas. Pessoas com esse perfil de preferência são capazes de ver as coisas como elas são e não como gostariam que fossem. Têm grande habilidade de discernir o que precisa ser feito em determinado momento, pois suas decisões são baseadas na análise lógica do pensamento e não apenas em seus valores pessoais, por isso, são ótimos para aliviar situações tensas. Também demonstram grande capacidade para a concentração. As pessoas que pertencem a esse tipo psicológico apresentam um bom desempenho em profissões nas quais a coragem física, o gosto pela ação e a capacidade de adaptar-se a diferentes situações estejam presentes. Assim, nesse tipo psicológico, pode-se verificar também que existem características psicológicas que se tornam pertinentes e importantes para quem desempenha a função de goleiro dentro de uma equipe de futebol de campo.

Tabela 1: Tipo psicológico dos goleiros profissionais e amadores

\begin{tabular}{|l|l|l|l|}
\hline Tipo psicológico & Profissionais & Amadores & Total \\
\hline I SsPs - sensação introvertida com pensamento & 3 & 4 & 7 \\
\hline I PsSs - pensamento introvertido com sensação & 1 & 1 & 2 \\
\hline I InPs - intuição introvertida com pensamento & 0 & 0 & 0 \\
\hline I Stln - sentimento introvertido com intuição & 0 & 0 & 0 \\
\hline I SsSt - sensação introvertida com sentimento & 1 & 1 & 2 \\
\hline I StSs - sentimento introvertido com sensação & 1 & 0 & 1 \\
\hline I InSt - intuição introvertida com sentimento & 0 & 0 & 0 \\
\hline E SsPs - sensação extrovertida com pensamento & 3 & 3 & 6 \\
\hline E PsSs - pensamento extrovertido com sensação & 1 & 1 & 2 \\
\hline E InSt - intuição extrovertida com sentimento & 0 & 0 & 0 \\
\hline E InPs - intuição extrovertida com pensamento & 1 & 1 & 2 \\
\hline E Psln - pensamento extrovertido com intuição & 0 & 0 & 0 \\
\hline E StSs - pensamento extrovertido com sensação & 1 & 1 & 2 \\
\hline E Stln - sentimento extrovertido com intuição & 2 & 1 & 3 \\
\hline E SsSt - sensação extrovertido com sentimento & 0 & 1 & 1 \\
\hline Total & $\mathbf{1 4}$ & $\mathbf{1 4}$ & $\mathbf{2 8}$ \\
\hline
\end{tabular}

\section{Considerações finais}

A partir dos resultados encontrados neste estudo, pode-se considerar que existem características psicológicas comuns a goleiros profissionais e amadores, tendo em vista que, dos dezesseis tipos psicológicos possíveis, predominaram dois tipos: sensação introvertida com pensamento e sensação extrovertida com pensamento, nos quais apenas a atitude variou. Além disso, a atitude dominante nos atletas, nos dois grupos, foi a extroversão, e a função psíquica, a sensação. O que pode ter contribuído para a similaridade no perfil encontrado entre os grupos de goleiros é o fato de que o teste utilizado no presente estudo trabalha com uma classificação por tipos, não captando as peculiaridades de cada indivíduo dentro de um perfil mais amplo. 
Evânea Scopel
Psicóloga, mestranda em Psicologia - Universidade Federal de Santa Catarina - UFSC

Alexandro Andrade

Docente do Programa de Mestrado em Ciências do Movimento Humano - coordenador do Laboratório de Psicologia do Esporte e do Exercício - LAPE - CEFID/UDESC

Daniela Centenaro Levandowski Psicóloga, Doutora em Psicologia do Desenvolvimento (UFRGS), docente do Curso de Graduação em Psicologia da Universidade de Caxias do Sul - UCS.

Universidade Federal de Santa Catarina Centro de Ciências Humanas e Filosofia Campus Universitário Trindade Cep: 88010-970 - Florianópolis (SC)

Tel: (48) 9979.0804 ou 248.8085 E-mail para contato: evânea@terra.com.br

ANDRADE, M. M. Introdução à Metodologia do Trabalho Científico. São Paulo: Atlas, 1999.

BARReto, J. A. Psicologia do Esporte para Atleta de Alto Rendimento. Rio de Janeiro: Shape, 2003.

BECKER, B. Manual de Psicologia do Esporte e do Exercício. Porto Alegre: Nova Prova, 2000.

BRANDÃO, M. R. Novas Tendências da Psicologia do Esporte na Perspectiva da Performance, Atividade Física e Qualidade de Vida. X Congresso Brasileiro - III Congresso Internacional de Psicologia do Esporte. Rio de Janeiro, set. 2003.

CLONINGER, S. Teorias da Personalidade. São Paulo: Martins Fontes, 1999.

DOMINGUES, A. Goleiro 100 Segredos. 20a ed. Curitiba: Verbo, 1997.

EPIPHANIO, E. H. Psicologia do Esporte: Apropriando a Desapropriação. Psicologia, Ciência e Profissão, 19 (3), pp. 70-73, 1999.

EGAN, S.; STELMACK, R.. A Personality Profile of Mount Everest Climbers. A Personality and Individual Differences, 32 (8), pp.14911494, 2003.

FADIMAN, J. Teorias da Personalidade. São Paulo: Harbra, 1986

FRANCO, G. S. Psicologia no Esporte e na Atividade Física. São Paulo: Manole, 2000

GARLAND, D.J. Personality and Leader Behaviors in Collegiate Football: a Multidimensional Approach to Performance. Journal of Research in Personality, 24 (3), pp. 355-370, 1990.

HALL, C. \& LINDZEI, G. Teorias da Personalidade. São Paulo: EPU, 1984.

JUNG, C.G. Tipos Psicológicos. 3ª ed. Rio de Janeiro: Zahar, 1976.
LUCCAS, A. N. Futebol e Torcidas: um Estudo Psicanalítico sobre o Vínculo Social. Dissertação de Mestrado. Programa de PósGraduados em Psicologia Social. PUC/SP, 1998.

MATARAZZO, F. Uma Investigação das Características Psicológicas em Atletas de Voleibol com Base na Tipologia de C. G. Jung. Monografia apresentada à Universidade de São Francisco. G. Jung. Monogra

RAMMINGER, T. Psicologia Comunitária X Assistencialismo: Possibilidades e Limites. Psicologia: Ciência e Profissão, 21 (1) pp.42-45, 2001.

RÚBIO, K. A Psicologia do Esporte: Histórico e Áreas de Atuação e Pesquisa. Psicologia: Ciência e Profissão, 19 (3), pp.60-69, 1999.

Encontros e Desencontros: Descobrindo a Psicologia do Esporte. São Paulo: Casa do Psicólogo, 2000.

Psicologia do Esporte: Interfaces, Pesquisa e Intervenção. São Paulo: Casa do Psicólogo, 2000

RÚDIO, F. V. Introdução ao Projeto de Pesquisa Científica. Petrópolis: Vozes, 1986.

SAMULSKI, D. Psicologia do Esporte. São Paulo: Manole, 2002.

SHARP, D. Tipos de Personalidade: o Modelo Tipológico de Jung. São Paulo: Cultrix, 1987.

VIANA, A.R. Treinamento do Goleiro de Futebol. Minas Gerais: Gav, 1995.

TUBINO, M.J.G. Metodologia Científica do Treinamento Desportivo. 11a ed. São Paulo: Ibrasa, 1984.

WEINBERG, R. S; GOULD, D. Fundamentos da Psicologia do Esporte e do Exercício. 2ª ed. Porto Alegre: Artes Médicas, 2001.

ZACHARIAS, J.J. de M. QUATI: Questionário de Avaliação Tipológica. Manual. São Paulo: Vetor, 1994.

ZACHARIAS, J.J. de M. QUATI: Questionário de Avaliação Tipológica. Manual. São Paulo: Vetor, 2000.
Referências 